\title{
R\&D investment and the arrangement of innovation capabilities in Brazilian manufacturing firms
}

\author{
Estêvão Passuello Ruffoni ${ }^{1^{*}}$, Fernando Antonio Monteiro Christoph $D^{\prime}$ Andrea ${ }^{1}$, Júlia Kich Chaves ${ }^{1}$, \\ Paulo Antônio Zawislak', Jorge Tello-Gamarra²
}

\begin{abstract}
This paper aims at identifying the different arrangements of innovation capabilities for firms with different levels of R\&D investment. The four innovation capabilities model (development, operations, management and transaction) by Zawislak et al., (2012) was crossed with the three level - low, medium and high - R\&D intensity classification by Legler and Frietsch (2007). A multiple regression was applied on data from a survey of 1,331 Brazilian manufacturing firms, results clearly show different arrangements of innovation capabilities for each level of R\&D investment. Operations capability does not generate innovation performance in any level. Development capability becomes increasingly relevant to performance, as R\&D investment increases, on the other hand, management and transaction capabilities turn to be less prominent.
\end{abstract}

Keywords: Innovation; R\&D Investments; Innovation Capabilities; Capabilities Arrangements

Submitted: August $30^{\text {th }}, 2018 /$ Approved: November $13^{\text {th }}, 2018$

\section{Introduction}

Traditionally, innovation studies at the firm level follow two perspectives: innovation as the result of R\&D investments and as the consequence of different innovation capabilities. However, although there is important research in each of these perspectives, studies that explicitly link them are scarce (see for example, Reichert et al., 2016; Rasiah et al., 2016; Chamsuk et al., 2017). The present paper goes exactly in the direction of better understanding the relation between R\&D investment and innovation capabilities.

In the first perspective, investments in $\mathrm{R} \& \mathrm{D}$ are a traditional indicator of innovation, both at the firm and macroeconomic levels. Different authors (e.g., Mansfield, 1980; Griliches, 1986; Gonzalez \& Gascon, 2004) have provided evidence pointing at the positive effects of R\&D investment over the increase of productivity and innovation. Firm's $\mathrm{R} \& \mathrm{D}$ intensities are usually measured based on the percentage of revenue invested in these activities (OECD, 2003; Legler \& Friestch, 2007).

Regarding the second perspective, the debate on how firms can build innovation capabilities goes back to the 1970's. In a broad sense, as stated by Richardson (1972), capabilities represent the firm's accumulation of knowledge, experience and skills, which will be responsible for the acquisition of competitive advantages. Later, Lall (1992), Bell and Pavitt (1993) trying to understand how product and process innovation emerge, proposed models for the technological capabilities of the firm. Recently, the concept of 'innovation capabilities' has been enlarged, it now goes beyond technological issues and considering organizational skills as important assets to build capabilities (Teece et al., 1997; Dosi, 2000). Recent innovation capabilities models (Guan \& Ma, 2003; Yam et al., 2011; Zawislak et al., 2012) seek to explain how different types of capabilities can be arranged to generate innovation.
Despite the development of those two perspectives, some issues can be raised, for example: How can one connect $R \& D$ investments with innovation capabilities? What are the different arrangements of capabilities for different levels of R\&D investment? Can a firm that invests little in $\mathrm{R} \& \mathrm{D}$ be innovative?

To answer these questions, the present study correlates Legler and Friestch's (2007) R\&D intensity classification with Zawislak et al.s (2012) innovation capabilities model. The paper uses a pre-existent database with a sample of 1,331 firms from different manufacturing sectors in Brazil to make a multiple linear regression. Three different optimal capability arrangements, one for each level of investment in $\mathrm{R} \& \mathrm{D}$, were obtained.

The use of Brazilian firms is justified by the country's industrial characteristics. At the same time, Brazilian industry holds a wide repertoire of sectors, such as food, metallurgy, machinery and equipment, chemistry, etc. (Reichert et al., 2015), and presents a great diversity of levels of R\&D investment between the companies (Furtado \& Carvalho, 2005). This research is expected to help companies on formulating innovation strategies according to their R\&D investment levels, as well as supporting the formulation of specific and appropriate public policy to foster innovation in firms at different levels of R\&D investment.

After this introduction, the paper is structured in six more sections: section 2 presents a brief literature review on $R \& D$ investments. Section 3 addresses the concepts of innovation capabilities, presenting the capabilities model deployed. Section 4 explains the method, the multiple linear regression, and why it was chosen. Sections 5 and 6 bring the results and discussions, respectively. Finally, Section 7 presents the concluding remarks.

(1) School of Management, Federal University of Rio Grande do Sul, Porto Alegre, Brazil.

(2) School of Chemistry and Food, Federal University of Rio Grande, Santo Antônio da Patrulha, Brazil.

*Corresponding author: epruffoni@hotmail.com 


\section{R\&D Investments}

Innovation studies have been mostly focused on the technological nature of the phenomenon. They usually try to understand how firms develop new products and processes. In this scenario, the amount of investment in R\&D activities is the most used indicator, and by far the longest standing (Smith, 2005). One of the first studies that seek to understand how technological innovation occurs was conducted by Utterback and Abernathy (1975). It shows how firms go from innovating in products to innovating in processes, as their technological base matures. Later, Pavitt (1984) identified that firms with higher levels of R\&D investment tend to innovate in products, while those with lower levels, tend to concentrate their activities in process innovation. While in-process innovation seeks to reduce production costs (Freeman \& Perez, 1988), it is expected that high R\&D investments lead firms to develop and introduce new products on the market (Freeman \& Soete, 1997). Since product innovation is much easier to notice than process innovation, firms that invest little in $R \& D$ are usually classified as less innovative.

The percentage of revenue invested in $R \& D$, or ' $R \& D$ investment', is often used to define the technological intensity of a given sector or firm (Godin, 2008). The Organization for Economic Cooperation and Development (OECD) (2003) developed a classification to categorize manufacturing sectors into four technological intensity levels. The parameter is the average percentage of revenue invested in $R \& D$ by firms belonging to each different sector. The levels are: Low technological intensity - up to $1 \%$ of the revenue invested in R\&D; Mediumlow technological intensity - more than $1 \%$ and up to $2.5 \%$ of the revenue invested in $\mathrm{R} \& \mathrm{D}$; Medium-high technological intensity - more than $2.5 \%$ and up to $7 \%$ of the revenue invested in R\&D; and High technological intensity - above $7 \%$ of the revenue invested in R\&D.

Based on OECD's classification, Legler and Frietsch (2007) have built a similar, but simpler, classification. It divides the levels in three different technological intensities: low - less than $2.5 \%$ of the revenue invested in $\mathrm{R} \& \mathrm{D}$; medium - from $2.5 \%$ to $7 \%$ of the revenue invested in $\mathrm{R} \& \mathrm{D}$; and high technological intensity - more than $7 \%$ of the revenue invested in $\mathrm{R} \& \mathrm{D}$.

The OECD's (2003) classification was used to identify innovation capabilities arrangements in firms of low technology industries by Reichert et al. (2016), and to analyze the innovation behavior of high technology and medium high technology industries by Villamizar et al., (2017). On the other hand, Legler and Frietsch's (2007) classification, for example, was applied by Kirner et al. (2009) to interpret the innovation behavior of firms that invest little in R\&D.

The use of R\&D investments as proxy for innovation has been, however, controversial. One of the problems with the industry-based classification is that it has been proposed and elaborated for the reality of developed countries - about $90 \%$ of the 35 OECD countries are developed (CIA, 2017). According to Furtado \& Carvalho (2005), in developing countries, such as Brazil, it is common to find firms that would be classified as high technological due to their sector, however, by concentrating on operational plants, doing very little or no development at all, and with much of the technology coming from abroad they end up behaving as low-technological (Reichert \& Zawislak, 2014). Those firms tend to follow headquarters' directives and focus their attention on improving production process, consequently, as aforementioned, they tend to hold lower levels of investment in R\&D. The pharmaceutical industry in Brazil (Malerba \& Mani, 2009) and India (Chittoor et al., 2008), as the electronics industry in China (Chittoor et al., 2008), are examples of this kind of phenomenon. Moreover, at the same time, some firms, belonging to low technological industries, such as food, rubber and metalworking, present higher levels of investment in R\&D (Furtado \& Carvalho, 2005).

The approach to innovation as a sole result of R\&D investments has also been criticized because it minimizes the innovativeness of the firm. As a result, firms with low levels of investment in R\&D end up being understood as non-innovators, which is not necessarily true. This approach does not perceive, due to the model's limitation, that innovation is more than traditional technology development in products and processes. Innovation also happens in organizational and marketing domains (Hirsch-Kreinsen, 2015, Reichert et al., 2016). The innovation capabilities approach, in turn, has a broader scope, analyzing the innovation phenomenon from a more complete perspective.

\section{Innovation Capabilities}

To be "capable" means to reach something that was intended, thus, the firm's capabilities fill the gap between the planned intention and the result achieved (Dosi, 2000). The term capability was firstly defined by Richardson (1972) as a set of experiences and knowledges accumulated over time by the firm. Later, Nelson and Winter (1982) stated that capabilities are connected to firms' ability to adapt its routines and skills according to the market and technological changes. Since those changes are unstoppable, capabilities must be dynamic to adapt the firm to those changes and allow for its survival (Teece et al., 1997). The result of this adaption process is innovation. Therefore, the most developed the dynamic capabilities are, the most innovative the firm will be and, as a consequence, the better will be its economic performance (Figueiredo, 2014).

From a Schumpeter' (1934) perspective, innovation capabilities should be understood by both a technological and a business driver. The technological driver encompasses innovation that arises from new products or new processes, in which the technological capability of Lall (1992) and Bell and Pavit (1993) stands out. The business driver deals with the importance of organizational change, the development of new strategies, and the adaptation to changing markets (Prahalad and Hamel, 1990). Teece et al., (1997) have a similar approach and highlights that the creation of value by a firm would not only be dependent on its technological assets, but also on organizational ones. Though, capabilities cannot be only built through investments in technology (Dosi, 2000). As a matter of fact, to transform any technology into an actual business, the company needs to create management routines and skills as well as to perceive and act upon market demands. 
Different models of innovation capabilities follow the two drivers' approach as, for instance, Guan and Ma (2003) and Yam et al., (2011). In the same path, Zawislak et al., (2012) suggested an objective and synthetic model. Each of the capabilities in the model represents a form of innovation, divided into the two drivers. The technological driver includes development (new products) and operations (new processes) capabilities while the business driver, management (new forms of organization) and transaction capabilities (new forms of marketing). Innovation performance thus depends on both drivers and on the different arrangements of capabilities. The innovation capabilities model is illustrated in Figure 1.

Figure 1 - Innovation Capabilities Model

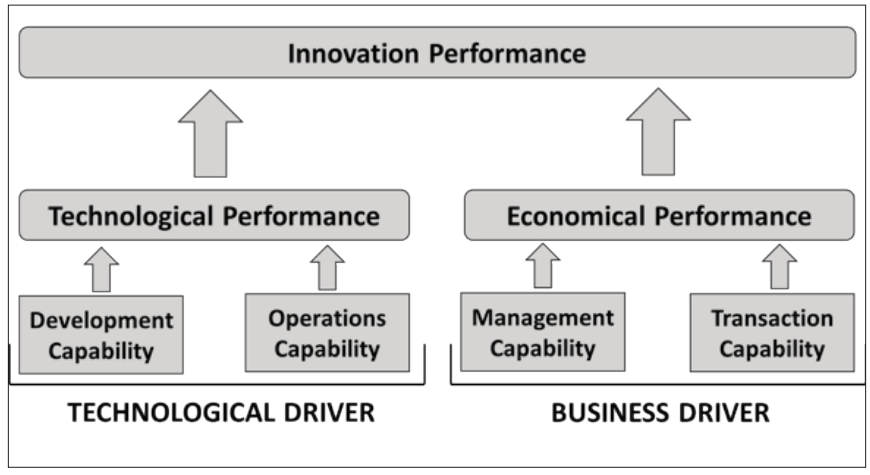

Source: Zawislak et al., (2012, 2013)

Development capability corresponds to the firm's routines and abilities to analyze the state of the art as well as to absorb, to adapt and to transform new technologies into new products (Bell \& Pavitt, 1993). The goal is to reach higher or new levels of technical and economic efficiency (Zawislak et al., 2012). Dutrénit (2000) states that this capability is related to the use that the firm has of its knowledge. It is the result of the learning processes by which the firm internalizes new knowledge to make technological change and, consequently, to develop new products (Lall, 1992).

Operations capability is related to the firm's routines and skills in organizing, planning, scheduling, preparing, executing and controlling its production (Reichert et al., 2015). According to Zawislak et al., (2012), since the development capability is responsible for creating new products, the operations capability is responsible for manufacturing them on a commercial scale. This capability is determined by the firm's knowledge of its production process. It results in new processes and new forms of manufacturing organization, aiming at generating competitive advantage generation through costs reductions, time to market decrease, and the improvement of product quality and of operation's flexibility (Hayes \& Pisano, 1994; Reichert et al., 2011).

Management capability is concerned with routines and skills for the best allocation of technological, material, financial and human resources (Lazonick, 1992). Unlike development and operations capabilities, it is not determined by applied knowledge (technology), but rather by a broader set of organizational skills (Langlois, 2003). It results in the implementation and use of new business models and new management tools, focusing on the efficiency of supporting processes to the firm's main activities (Barnard, 1966; Chandler, 1977; Teece et al., 1997; Zawislak et al., 2012, 2013).

Finally, transaction capability corresponds to ability and routines to minimize the transaction costs and deal with the marketing activities. For Zawislak et al., (2012), once a technological solution has been developed, produced and managed, the firm must turn its efforts to its commercialization. This capability is characterized by research and relationship with the market, search of suppliers and customers, brand development, service and negotiation, product sales, logistics process (supplies and distribution) and after-sales (Reichert et al., 2015). Its results are perceived through new forms of commercialization, new sales channels, new market niches, new brands, new services (Hirsch-Kreinsen, 2008), or new suppliers and supply processes, with lower costs than current ones (Zawislak et al., 2012, 2013).

After explaining the capabilities model, it remains to be known how those capabilities can be arranged to generate innovation in firms with different levels of investment in R\&D. For that, the next session presents the research method.

\section{Research Method}

The present study made use of a database from NITEC (Innovation Research Centre), a research group linked to UFRGS (Federal University of Rio Grande do Sul). The database is the result of a survey conducted in 2014, which aimed to analyze the innovativeness of Brazilian manufacturing firms. The survey resulted in 1,331 valid questionnaires. The questions asked are presented in a five-point Likert scale, where 1 corresponds to totally disagree, and 5 to strongly agree. Questions were divided into four blocks of firms' capabilities (7 items related to development capability, 9 to operations capability, 7 to management capability, and 6 to transaction capability) and a block of innovation performance ( 3 items), totaling 32 items. In addition to these items, there are general questions about the company, in which the percentage of revenue invested in $\mathrm{R} \& \mathrm{D}$ is asked.

In order to meet the paper's objectives, the following statistical techniques were used: mean, standard deviation, factorial analysis and multiple regression. We used Microsoft Excel 2013 and SPSS (Statiscal Package for Social Sciences) version 18.

Firstly, sample's firms were grouped according to their respective R\&D investment level. The present research used Legler and Frietsch's approach (2007) at the firm level due it better compatibility with the sample characteristics - there are large differences between the percentages of revenue invested in $\mathrm{R} \& \mathrm{D}$ among firms that belong to the same industry, which would distort the data at the sector level. According to Kirner et al. (2009) the main problem with a sectoral analyzes is that it does not take into account differences at the firm level. In order to clean the database, non-respondents (59 in total) and firms reporting R\&D investments above three standard deviations of the mean were eliminated. The mean $\mathrm{R} \& \mathrm{D}$ investment level of the whole sample is $4.05 \%$, and the standard deviation is $6.50 \%$. Firms that 
responded to invest $23.5 \%$ or more of their revenue in $R \& D$ were eliminated (14 in total). Such high values are considered unrealistic because, for example, the company that invests the most in R\&D worldwide puts $17 \%$ of its revenue in those activities (Casey \& Hacket, 2014). The final sample consisted of 1,258 firms, corresponding to $94.5 \%$ of the total. Table 1 illustrates.

Table 1 - Dataset

\begin{tabular}{|c|c|c|c|}
\hline$R \& D$ investment level & Rate of the revenue invested on $R \& D$ & Companies & Rate of Total of companies \\
\hline Low & From $0.00 \%$ to $2.50 \%$ & 676 & $50.79 \%$ \\
\hline High & Above $7.00 \%$ & 216 & $16.23 \%$ \\
\hline \multicolumn{2}{|c|}{ Number of Companies considered in the Analysis } & 1.258 & $94.52 \%$ \\
\hline \multicolumn{2}{|c|}{ Total number of excluded } & 73 & $5.48 \%$ \\
\hline \multicolumn{2}{|c|}{ Total number of companies } & 1.331 & $100 \%$ \\
\hline
\end{tabular}

Factor analysis was used to scrutinize the sample. This technique defines factors (constructs), and it also determines which items of each factor will or will not be included in the analysis according to their relative relevance to that particular factor (Green \& Salkin, 2014). As factors are composed by sets of items, factor analyzes can be understood as a simplifying data technique (Hair et al., 2009). The type of factor analysis used was the PCA (Principal Component Analysis), with orthogonal rotation Varimax, which, according to Hair et al., (2009), facilitates the results' interpretation.
The 32 surveys items should generate different factors: one for each innovation capability, plus one for innovation performance. However, the first round of PCA presented six different factors. In this analysis, nine items had factorial loads lower than .5, which are considered unsatisfactory (Hair et al., 2009), and those nine items were excluded. The remaining 23 items were used in a second PCA analysis in which all factor loads where higher than .5 and that obtained the five factors predicted by the theory. Table 2 illustrates the survey items that were considered in the final analysis.

Table 2 - Remaining items and factors

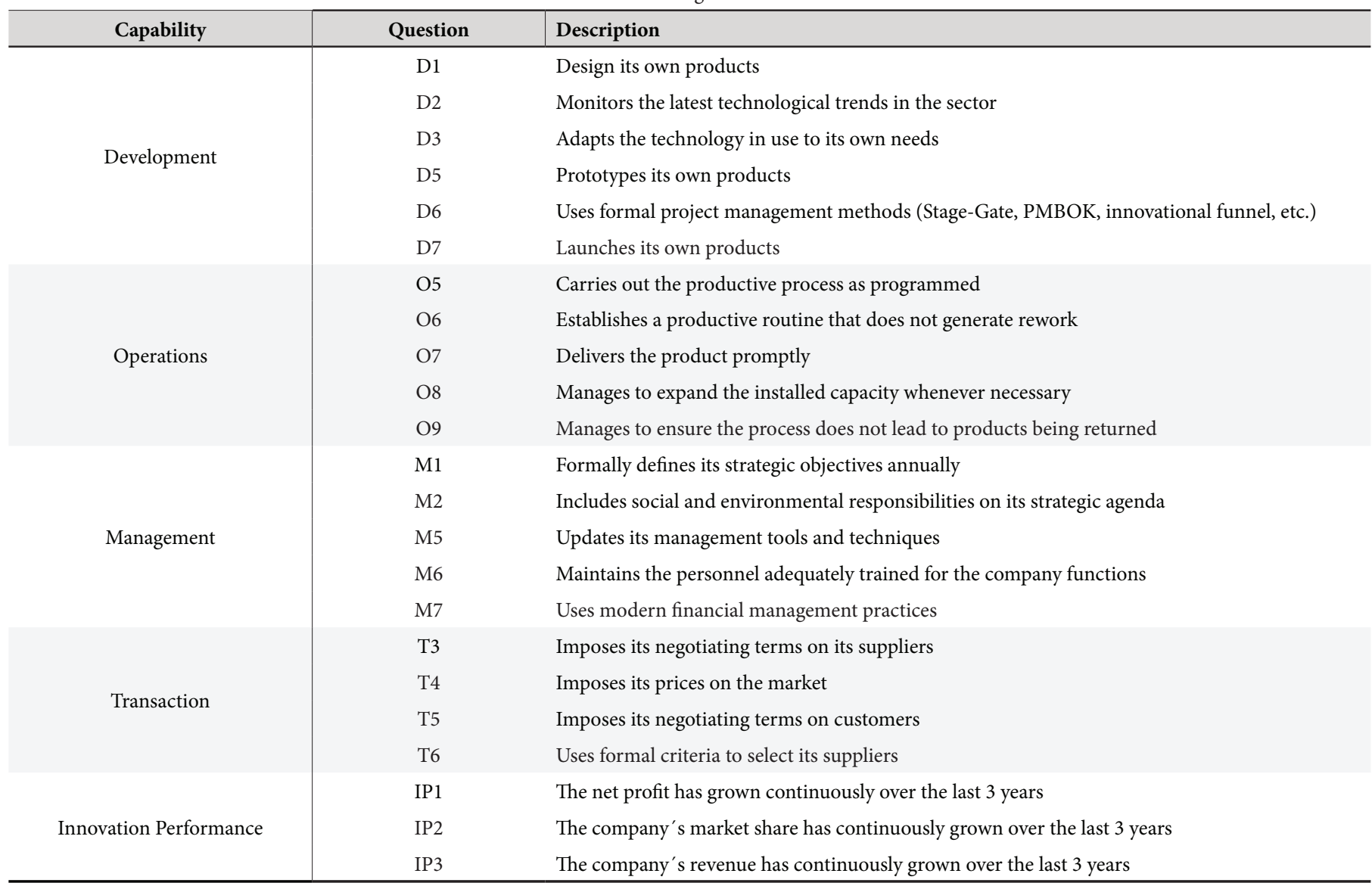


The KMO (Kayser-Meyer-Olkin) test was applied to check the efficiency of the factor analysis: the result of .893 indicates that the PCA that was applied produced internally different and reliable factors (Kaiser, 1974; Field, 2009). In addition, the Barlett test results was bellow .001, also indicating the adequacy of the factor analysis (Hair et al., 2009). The total variation explained by the four factors related to innovation capability is $61.3 \%$.

After the PCA, the multiple regression analysis was conducted. This analysis is indicated when the aim is to find the relationship between one dependent variable and more than one independent variables (Hair et al., 2009). In the present study, each of the four innovation capabilities represents an independent variable, while innovation performance is the dependent one. The objective is to find a equation whose coefficients ( $\Omega^{\prime}$ s) demonstrate the importance of each capability to performance, in a similar fashion to what was proposed by Alves et al., (2017) in Equation 1.

$$
\mathrm{IP}=\beta_{0}+\beta_{1} \mathrm{DC}+\beta_{2} \mathrm{OC}+\beta_{3} \mathrm{MC}+\beta_{4} \mathrm{TC} \text { Equation } 1
$$

The innovation performance (IP) is a function of $\beta 0$, a constant that represents the minimum legal, technological and economic requirements for the existence of any firm in a given sector, plus the $\beta$ of each capability (DC for development, OC for operations, MC for management and TC for transaction). The $ß$ of the capabilities determine the importance of each one for the innovation performance, thus defining the capabilities arrangement necessary for the firm's competitiveness. An equation was identified for each level of R\&D investment - low, medium and high, as the next session presents.

\section{Results}

For each level of investment in $\mathrm{R} \& \mathrm{D}$, a table with the non-standard coefficients ( $\mathrm{B}$ and the standard error) is presented, as the coefficient $(B)$, and the value of the test $t$ - determining the significance of the capabilities. Values above 0.001 were considered non-significant (Hair et al., 2009). When talking about the coefficients, the higher are their values, the greater is the importance of capability for the innovation performance. At the same time, for each of the equations, a value of $\mathrm{R}^{2}$ was also obtained. This value indicates how much the result of the dependent variable is explained by the independent variables. According to Hair et al., (2009), the higher the $\mathrm{R}^{2}$, the higher the level of explanation of the independent variables over the dependent one.

With respect to $\mathrm{R}^{2}$ values that were found, it should be pointed out that the innovation capabilities model only analyzes the firm, and considers that all external factors (for example, the influence of the legal environment, sector specificities, and more general macroeconomics issues) impact on firms' innovation performance at the same time, in a more or less similar way. Thus, it is suggested that the environment corresponds approximately to three-quarters of factors influencing firms, while the remaining $25 \%$ of factors stay under the control of organizations. Because of that, the $\mathrm{R}^{2}$ values were expected to be under the limit of .25 .

\section{Innovation capabilities arrangement for firms with low investment in $R \& D$}

For low $\mathrm{R} \& \mathrm{D}$ investment firms, the $\mathrm{R}^{2}$ is .232 , representing a high level of explanation by the applied capabilities model. Analyzing the coefficients and the significance from each of the capabilities, the most relevant ones for innovation are: management (.232), transaction (.222) and development (.165) respectively. The operations capability is considered not significant for this group.

Table 3 - Results for firms with low investment in R\&D.

\begin{tabular}{cccccc}
\hline Capability & B & $\begin{array}{c}\text { Standard } \\
\text { Error }\end{array}$ & $\begin{array}{c}\text { Coefficients } \\
(\mathbb{\Xi})\end{array}$ & $\mathrm{T}$ & Sig. \\
\hline Constant & -.079 & .041 & & -1.951 & .052 \\
Development & .165 & .045 & .165 & 3.692 & .000 \\
Operations & .019 & .045 & .019 & .423 & .672 \\
Management & .246 & .045 & .232 & 5.473 & .000 \\
Transaction & .220 & .040 & .222 & 5.550 & .000 \\
\hline $\mathrm{n}=676$ & & & & &
\end{tabular}

Therefore, for companies that do not invest, or invest a very small part of their revenue in R\&D activities, innovation can be achieved through new management models that reduce administrative costs and create organizational efficiency. In these cases, innovation also can be obtained by new forms of transaction with the market, such as new ways of product selling, or new logistics and distribution techniques, which provide lower transactional costs, as the reach of new clients and new suppliers.

Likewise, these firms should focus their innovation efforts on product development activities, although they are not as necessary. New product development activities should involve the absorption of technologies from their suppliers, especially from machinery and raw materials ones, which will allow them to increase the quality of their products (Hirsch-Kreinsen, 2008, 2015). Thus, the innovation strategy of low R\&D firms must be focused, firstly, on the cost reduction of managerial and transactional process. On a secondary level, these firms must establish routines and skills for improve products quality (Reichert et al., 2016). Equation 2 illustrates the capabilities arrangement that brings innovation for this group of firms (considering only the significant capabilities).

$I P=-0.079+0,232^{\star} M C+0,222^{\star} T C+0,165^{*} D C+e \quad$ Equation 2

\section{Innovation capabilities arrangement for firms with medi- um investment in R\&D}

In this level of investment, the $\mathrm{R}^{2}$ is .194 , still with a high explanation level. The coefficients, associated with the significance of the constructs, indicates the relevance of the development capability (.300) and of the management one (.188). Operations and transaction capabilities were not significant. 
The higher importance of the development capability is easy to observe, as well as the smaller relevance of the management capability when compared to low R\&D investment firms. Thus, for medium R\&D investment firms, innovation comes mainly from the development of new products, supported by new managerial models.

Table 4 - Results for firms with medium investment in R\&D

\begin{tabular}{cccccc}
\hline Capability & $\mathrm{B}$ & $\begin{array}{c}\text { Standard } \\
\text { Error }\end{array}$ & $\begin{array}{c}\text { Coefficients } \\
(\mathbb{\nabla})\end{array}$ & $\mathrm{T}$ & Sig. \\
\hline Constant & .120 & .044 & & 2.698 & .007 \\
Development & .274 & .054 & .300 & 5.108 & .000 \\
Operations & .009 & .053 & .010 & .170 & .865 \\
Management & .178 & .052 & .188 & 3.385 & .001 \\
Transaction & .077 & .055 & .078 & 1.404 & .161 \\
\hline $\mathrm{n}=366$ & & & & &
\end{tabular}

The innovation strategy in this group is based on the adaption of technological novelties, that emerge from firms with higher investments levels in R\&D - those companies do not just simply copy new products, they do try to improve upon previously existent products, a feature that demands more elaborated technological routines and skills (Freeman \& Soete, 1997). As their new products do not allow a temporary market monopoly, these firms also need to innovate in the management techniques to reduce administrative costs, and improve profit margins. Equation 3 summarizes the arrangement required for medium R\&D investment firms (presenting only significant innovation capabilities).

$$
\mathrm{IP}=0,120+0,300^{\star} \mathrm{CD}+0,188^{\star} \mathrm{CG}+\mathrm{e} \quad \text { Equation } 3
$$

\section{Innovation capabilities arrangement for firms with high investment in R\&D}

The $\mathrm{R}^{2}$ for high $\mathrm{R} \& \mathrm{D}$ firms is .177, maintaining the elevated explanation power of the capabilities model. For this group, the only significant capability is the development one, presenting a coefficient at .316. The other three capabilities: management, transaction and operations, are not significant.

The development capability importance increased when compared to the medium R\&D firms. Since innovation can only be reached by the development capability, these firms should focus all their innovation efforts on the development of new products. The elevated amounts of capital invested in $\mathrm{R} \& \mathrm{D}$ activities involves severe risks, and because of it, these firms must generate radical innovations, with brand new products.

Finally, Table 5 shows the results for firms with high investments in R\&D.
Table 5 - Results for firms with high investment in R\&D

\begin{tabular}{cccccc}
\hline Capability & B & $\begin{array}{c}\text { Standard } \\
\text { Error }\end{array}$ & $\begin{array}{c}\text { Coefficients } \\
(\mathbb{\nabla})\end{array}$ & $\mathrm{T}$ & Sig. \\
\hline Constant & 0,075 & 0,067 & & 1,120 & 0,264 \\
Development & 0,352 & 0,086 & 0,316 & 4,081 & 0,000 \\
Operations & 0,078 & 0,070 & 0,083 & 1,114 & 0,266 \\
Management & 0,078 & 0,068 & 0,087 & 1,158 & 0,248 \\
Transaction & 0,027 & 0,070 & 0,026 & 0,380 & 0,704 \\
\hline $\mathrm{n}=216$ & & & & &
\end{tabular}

Commonly this kind of innovation fills demand gaps, establishing new patterns of productivity and consumption in the market (Freeman \& Perez, 1988). With that, the firms could obtain Schumpeterian profits for determined period, compensating the risks involved on their R\&D activities. The results demonstrate the overwhelming importance of routines and skills for transform new technologies in new products, overlapping the transactional, managerial and operational ones, in such way that they even do not even matter for innovation performance, in this group. Equation 4 illustrates the capabilities arrangement for the high R\&D firms (considering only the significant ones).

$$
I P=0,075+0,316 D C+e \quad \text { Equation } 4
$$

\section{Discussion}

Figure 1 summarizes the results and presents the capabilities arrangements obtained for each of the three levels of R\&D investment, demonstrated by the coefficients obtained for capabilities on each R\&D investment level.

Figure 2 - R\&D Investment Levels versus Innovation Capabilities Arrangements

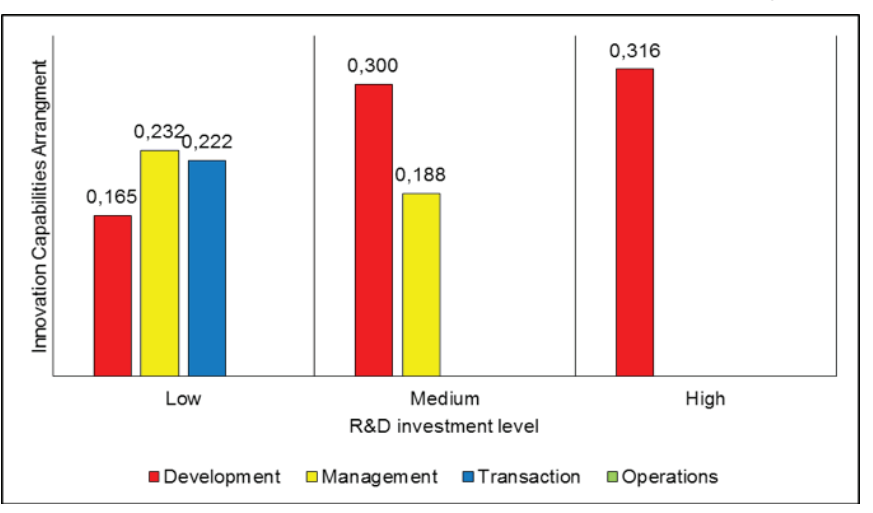

The first aspect observed is the operations capability irrelevance on all levels of investment in R\&D. Alves et al., (2017) have already demonstrated, in a study carried out with the same database and with the innovation capabilities model, that the operations capability is not able to generate competitive advantages and differentiation between firms. It is 
thus considered an 'ordinary capability', that is not really able to generate innovation in this context. The operations capability is, of course, relevant for the firm existence, but does not have a significant influence on the innovation performance. Nevertheless, this capability is the most prominent in the sample's firms (Reichert et al., 2015). It is understood that this phenomenon occurs because innovation efforts related to operations capability are standardized among the sample: all firms use similar equipment, and all of them apply very similar techniques for the process organization, planning, scheduling setup, execution and control. Thus, when a capability cannot generate differentiation between peers, it hardly provides innovation (Nelson \& Winter, 1982).

Secondly, as R\&D investments increase, there is a gradual lost of relevance of business driver innovation capabilities (management and transaction). At the same time, development capability becomes more important. That is, as companies invest in R\&D activities, they increase their routines and skills to monitor, absorb, adapt and transform technologies in new products, giving less relevance to those capabilities attached to organizational innovation.
Somehow, it is as if the business driver capabilities end up compensating the little elaborated development capability, which is a consequence of the low levels of revenue invested in R\&D. This corroborates to the thesis of organizational innovation importance for firms that do not invest, or invest low values in R\&D (Christensen, 1994, Kirner et al., 2009, Hirsch-Kreinsen, 2015, Reichert et al., 2016).

Furthermore, for firms with low R\&D investment the only ordinary capability, i.e. the only one which was irrelevant for the innovation performance, was the operations one. For firms with medium investment levels, the transaction capability also became irrelevant (beyond operations capability), and finally, for high investors, all others became ordinary, except for the development capability.

Regarding the average of firm's capabilities by level of investment in R\&D (See Table 6), it can be observed that capabilities naturally increase in accordance with the increase of $R \& D$ investment levels. Table 6 illustrates this situation, analyzing survey items averages related to the capabilities.

Table 6 - Average of firms capabilities by level of investment in R\&D

\begin{tabular}{ccccc}
\hline \multirow{2}{*}{ R\&D Investment Level } & \multicolumn{3}{c}{ Capabilities Averages $^{\mathrm{a}}$} \\
& Development & Operations & Management $^{\text {Transaction }}$ & 3,38 \\
Low & 3,46 & 3,95 & 3,99 & 3,61 \\
Medium & 3,72 & 3,93 & 4,10 & 3,84 \\
High & 4,15 & 4,19 & & 3,38 \\
\hline
\end{tabular}

${ }^{a}$ Capability are presented in a five-point Likert scale (1: totally disagree and 5: strongly agree)

The data shows that, the more elaborated and standardized the firm's capabilities become (when compared to their competitors), the less able they are to have some impact on innovation performance (IP). In those cases, having very high levels of all other capabilities (except for the development one) becomes irrelevant when it comes to differentiate the firms from its competitors in the market. That replicates the phenomenon observed by Alves et al., (2017) over the operations capability. Although this idea finds support in the data, more research on this topic is needed, adding specificities and comprehensiveness. If results are corroborated than it would be safe to state categorically that this phenomenon is something repetitive and constant.

\section{Concluding Remarks}

This article has identified innovation capabilities arrangements for firms at different levels of R\&D investment. The different arrangements signalize which forms of innovation can differentiate companies in their respective markets, and thus achieve a satisfactory economic performance. The levels of investment in R\&D were defined using the Legler and Frietsch (2007) model, which establishes three levels - low, medium and high. To identify the capabilities arrangements, the multiple linear regression method was applied, based on Zawislak et al., (2012) four firm's innovation capabilities model - development, operations, management and transaction.
The results demonstrated that, at each level of investment in R\&D, any firm demands a specific capabilities' arrangement for reach innovation. Firms with low R\&D investment level should innovate through management, transaction and development capabilities. They must focus their innovation efforts on reducing managerial and transactional processes costs, as well as seeking for absorb new technologies from their suppliers, aiming to improve the quality of their products.

Meanwhile, firms with medium R\&D investment levels must innovate through development and management capabilities. This kind of firm doesn't innovate through the transaction capability (minimize transaction cost and marketing activities), but rather from the improvement of products developed. This strategy does not allow them to obtain Schumpeterian extraordinary profits, so the optimization of managerial processes is necessary to reduce costs, and increase the margins.

Finally, high R\&D investment firms innovate only by development capability. This level consist on firms that must be highly focused on the elaboration of new products, establishing radical innovations, as well new standards of productivity and consumption in the markets.

Operations capability has not demonstrated relevance for firm's innovation performance at any level of R\&D investment. It's understood that since mostly firms in the sample possess standardized 
operational routines and skills, this capability is not able to differentiate the firm from their competitors, and thus fails to generate innovation. It's also observed that as the level of R\&D investment increases, the less relevant become the business driver capabilities (management and transaction), and more relevant become the development capability. It is inferred, therefore, that business driver capabilities end up compensating the lack of well elaborated development routines and skills - likewise, the development capability prominence dispenses the need of management and transaction capabilities for innovation.

The managerial implications of these results are relevant with regard to the innovation strategy to be adopted. Firms do not necessarily need to invest high amounts of capital on R\&D activities to innovate. Even firms that adopt a more conservative stance, not taking risks with investments in technology, can innovate through new models of management and of transaction with the market. But if the firm really wants to develop new products, revolutionize its market, and reap the gains from it, it needs to invest high R\&D values.

Regarding the policy implications, it should be emphasized that governmental actions must take into account the suggestions presented in this research. In particular, policymakers should be careful while developing policies to foster expenditures on technological innovation. The paper shows that not all companies will innovate in the same way, thus a policy that fosters one specific kind of innovation can be detrimental to the overall innovation performance (and consequently to financial performance) of firms. Policymakers should have in mind that the set of companies under their umbrella is very broad and perhaps R\&D investment is not so relevant to innovation in that particular environment.

Two future researches can be developed based on this paper's results. The first would be the conduction of this analysis with data coming from different parts of the world, either emerging, developed or developing countries. It would be interesting to understand the distinct capabilities arrangements for different R\&D levels in diverse macro-economic realities and economic sectors (e.g. agribusiness and services). The second one relates to a deeper analysis over an important observation: the lost of capabilities relevance for innovation. The higher the level of investment in $\mathrm{R} \& \mathrm{D}$, the more elaborate are the firms' capabilities, and more capabilities became ordinary - only one capability is ordinary on low R\&D level, but two became ordinary on medium R\&D level, and three on high R\&D level. Further research could be carried out in this sense, contributing to better understanding of the innovation capabilities importance.

\section{Acknowledgements}

The present study received financial support from the Brazilian National Council for Scientific and Technological Development (CNPq) and from the State of Rio Grande do Sul Research Foundation (FAPERGS).

\section{References}

Alves, A.C., Barbieux, D., Reichert, F.M., Tello-Gamarra, J. \& Zawislak, P. A. (2017). Innovation and dynamic capabilities of the firm: defining an assessment model. Revista de Administração de Empresas, 57 (3), 232-244.doi.org/10.1590/s0034-759020170304.
Barnard, C. (1966). The Functions of the Executive. Cambridge, Inglaterra: Harvard University Press.

Bell, M. \& Pavitt, K. (1993). Technological Accumulation and Industrial Growth: Contrast between Developed and Developing Countries, Industrial and Corporate Change, 2(1), 157-210.

Casey, M. \& Hackett, R. The 10 biggest R\&D spenders worldwide. Fortune, 2014. Avaliable at: http://fortune.com/2014/11/17/top10-research-development/ Visited on: May 16 ${ }^{\text {th }}, 2018$.

CIA Central Intelligence Agency (2017). The World Factbook 2017. Washington, D.C.: CIA. Retrieved https://www.cia.gov/library/publications/the-world-factbook/. Visited on: July, 29 ${ }^{\text {th }}, 2017$.

Chandler, A. D. (1977). The visible hand. Cambridge, Mass. and London, England: The Belknap Press of Harvard University Press.

Chittoor, R., Sarkar, M., Ray, S., \& Aulakh, P, S. (2008). ThirdWorld Copycats to Emerging Multinationals: Institutional Changes and Organizational Transformation in the Indian Pharmaceutical Industry. Organization Science, 20(1), 187-205. doi.org/10.1287/ orsc. 1080.0377.

Christensen, J. F. (1994). Asset profiles for technological innovation. Research Policy, 24 (5), 727-745.doi.org/10.1016/00487333(94)00794-8.

Chamsuk W., Fongsuwan, W. \& Takala, J. (2017). The effects of $\mathrm{R} \& \mathrm{D}$ and innovation capabilities on the thai automotive industry part's competitive advantage: a sem approach. Management and Production Engineering Review, 8(1), 101-112. DOI: 10.1515/ mper-2017-0011

Dosi, G; Nelson, R. \& Winter, S. (2000). The Nature and Dynamics of Organizational Capabilities. In: United States of America: Oxford University Press, 2000.

Dutrénit, G. (2000). Learning and Knowledge management In the firm: from knowledge accumulation to strategic capabilities. Cheltenham: Edward Elgar, Northampton, Ma.

Field, A. (2009). Discovering statistics using SPSS, 3rd Edition. London: Sage.

Figueiredo, P.N. (2014). Beyond technological catch-up: an empirical investigation of further innovative capability accumulation outcomes in latecomer firms with evidence from Brazil. Journal of Engineering and Technology Management, 31, 73-102. doi.org/10.1016/j.jengtecman.2013.10.008

Freeman, C., \& Perez, C. (1988). Structural crises of adjustment, business cycles and investment behaviour. In: DOSI, G. Technical Change and Economic Theory. Pinter Publishers, 38-66.

Freeman, C., Soete, L. (1997). The Economics of Industrial Innovation, 3rd ed. Pinter, London. 
Furtado, A. T., \& Carvalho, R. Q. (2005). Padrões de intensidade tecnológica da indústria brasileira: um estudo comparativo com os países centrais. São Paulo em Perspectiva, 19(1), 70-84.

Green, S. B., \& Salkind, N. J. (2014). Using SPSS for Windows and Macintosh: Analyzing and understanding data. Seventh Edition, Pearson.

Griliches, Z., 1986. Productivity, R\&D, and basic research at the firm level in the 1970's. American Economic Review, 76 (1), 141-154.

Godin, B. The moral economy of technology indicators. (2008). In Hirsch-Kreinsen, H., \& Jacobson, D. (Eds.). Innovation in low-tech firms and industries. Edward Elgar Publishing, 64-84.

Gonzalez, E., Gascon, F. (2004). Sources of productivity growth in the Spanish pharmaceutical industry (1994-2000). Research Policy, 33 (5), 735-745. doi.org/10.1016/j.respol.2003.12.004.

Guan, J., \& Ma, N. (2003). Innovative capability and export performance of chinese firms. Technovation, 23, 737-747. doi.org/10.1016/ S0166-4972(02)00013-5.

Hair, J. F., Black, W. C., Babin, B. J., Anderson, R. E., \& Tatham, R. L. (2009). Análise multivariada de dados. 6a Edição. Bookman Editora.

Hayes, R. H., \& Pisano, G. P. (1994). Beyond world-class: the new manufacturing strategy. Harvard Business Review, 77-86.

Hirsch-Kreinsen, H. (2015). Innovation in low-tech industries: current conditions and future prospects. In SOM, O. and KIRNER, E. (Eds). Low Tech Innovation - Competitiveness of German Manufacturing Sector. Springer International Publishing, p. 17-32.

Hirsch-Kreinsen, H. (2008). Low-technology: a forgotten sector in innovation policy. Journal of technology management \& innovation, v. 3, n. 3, p. 11-20. Retrieved from: http://www.oecd.org/std/its/41419823.ppt .

Kaiser, H. F. (1974). An index of factorial simplicity. Psychometrika, 39(1), 31-36.

Kirner, E., Kinkelm, S., Jaeger, A. (2009). Innovation Paths and the Innovation Performance of Low-Technology Firms - An Empirical Analysis of German Industry. Research Policy, Special Issue: Innovation in Low-and Meduim-Technology Industries, 38 (3), 447-458. doi.org/10.1016/j.respol.2008.10.011.

Lall, S. (1992). Technological capabilities and industrialization. World Development, 20(2), 165-186. doi.org/10.1016/0305-750X(92)90097-F.

Langlois, R. N. (2003). The vanishing hand: the changing dynamics of industrial capitalism. Industrial and corporate change, 12 (2), 351-385. doi.org/10.1093/icc/12.2.351.

Lazonick, W. (1992). Business Organization and Competitive Advantage: Capitalist Transformations in the Twentieth Century. In: DOSI, G.; GIANETTI, R. e TONINELLI P. A. Technology and Enterprise in a Historical Perspective. England: Oxford University Press, 119-163.
Legler, H. \& Frietsch, R. (2007). Neuabgrenzung der Wissenswirtschaft - forschungsintensive Industrien und wissensintensive Dienstleistungen. NIW/ISI-Listen 2006. Studien zum deutschen Innovationssystem Nr. 22. Hannover, Karlsruhe: Fraunhofer ISI.

Malerba, F., \& Mani, S. (2009). Sectoral Systems of Innovation and Production in Developing Countries: Actors, Structure and Evolution. Edward Elgar Publishing.

Mansfield, E., (1980). Basic research and productivity increase in manufacturing. American Economic Review 70 (5), 863-873.

Nelson, R. R., \& Winter, S. G. (1982). An evolutionary theory of economic change. Cambridge (Ma): The Belknap Press of Harvard University Press.

OECD - Organization for Economic Cooperation and Development (OECD) (2003), Science, Technology and Industry Scoreboard, OECD, Paris.

Pavitt, K. (1984). Sectoral patterns of technical change: towards a taxonomy and theory. Research Policy, 13, 343-373.

Prahalad, C., \& Hamel, G. (1990). The core competence of the corporation. Harvard Business Review, 68 (3), p. 79-91.

Rasiah, R., Shahrivar, R.B., Yap, X.S. (2016). Institutional support, innovation capabilities and exports. Technol. Forecast. Soc. Chang. 109 (1), 69-75. doi.org/10.1016/j.techfore.2016.05.015.

Reichert, F.M.; Beltrame, R.S.; Corso, K.B.; Trevisan, M.; Zawislak, P. (2011). Technological capability predictor variables. Journal of Technology, Management \& Innovation, 6 (1), 14-25.

doi.org/10.4067/S0718-27242011000100002.

Reichert, F. M., Torugsa A, N., Zawislak, P. A., \& Arundel A. (2016). Exploring innovation success recipes in low-technology firms using fuzzy-set QCA. Journal of Business Research, v.69, p. 5437-5441. doi. org/10.1016/j.jbusres.2016.04.151.

Reichert, F. M., Camboim, G. F., \& Zawislak, P. A. (2015). Capacidades e trajetórias de inovação de empresas brasileiras. Revista de Administração Mackenzie, 16(5), 161-1994. doi.org/10.1590/167869712015/administracao.v16n5p161-194.

Reichert, F.M. \& Zawislak, P.A. (2014). Technological capability and firm performance. Journal of Technology, Management \& Innovation, 9 (4), 20-35. doi.org/10.4067/S0718-27242014000400002.

Richardson, G. B. (1972). The organisation of industry. The Economic Journal, 82(327), 883-896.

Schumpeter, J. A. (1942). Capitalism, Socialism and Democracy. New York, EUA: Harper.

Schumpeter, J. (1934). The Theory of Economic Development, Harvard University Press, Cambridge, MA. 
Smith, K., 2005. Measuring innovation. In: Fagerberg, J., Mowery, D., Nelson, R. (Eds.), The Oxford Handbook of Innovation. Oxford University Press, Oxford, pp. 148-179.

Teece, D. J., Pisano, G., \& Shuen, A. (1997). Dynamic capabilities and strategic management. Strategic Management Journal, 18(7), 509-533.

Utterback, J. M., \& Abernathy, W. J. (1975). A dynamic model of process and product innovation. Omega, v. 3, n. 6, p. 639-656.

Villamizar, M.A.; Cobo, A.; Rocha, R. (2017). Characterisation of the manufacturing sectors of high and medium-high technology compared with other industrial sectors. Journal of Technology, Management \& Innovation, 12 (1), 39-48. doi.org/10.4067/S071827242017000100005.
Yam, R., Guan, J., Pun, K., \& Tang, E. (2011). An audit of technological innovation capabilities in Chinese firms: some empirical findings in Beijing, China. Research Policy, 33(8), 1123-1140. doi.org/10.1016/j. respol.2004.05.004.

Zawislak, P. A., Alves, A., Tello-Gamarra, J., Barbieux, D., \& Reichert, F. M. (2013). Influences of the internal capabilities of firms on their innovation performance: a case study investigation in Brazil. International Journal of Management, 30(1), 329-348.

Zawislak, P. A., Alves, A., Tello-Gamarra, J., Barbieux, D., \& Reichert, F. M. (2012). Innovation capability: from technology development to transaction capability. Journal of Technology Management \& Innovation, 7(2), 14-27. doi.org/10.4067/S0718-27242012000200002. 